\title{
POLITICAL JUSTIFICATIONISM: A CASUISTIC EPISTEMOLOGY OF POLITICAL DISAGREEMENT
}

\author{
Jay Carlson \\ Loyola University-Chicago
}

\begin{abstract}
The conciliationist and steadfast approaches have dominated the conversation in the epistemology of disagreement. In this paper, drawing on Jennifer Lackey's justificationist approach and the casuistry paradigm in medical ethics, I will develop a more contextual epistemology of political disagreement. On this account, a given political disagreement's scope, domain, genealogy, and consequence can be helpful for determining whether we should respond to that disagreement at the level of our confidence, beliefs, or with policy. Though some may argue that responding with policy is a practical consideration instead of an epistemic matter, I argue that even policy responses to disagreements have an epistemic dimension to them that we should not ignore.
\end{abstract}

Keywords: epistemology of disagreement, political disagreement, casuistry, justificationism, Jennifer Lackey

DOI: https//doi.org/10.3176/tr.2020.3.05

\section{Introduction}

The epistemology of disagreement literature centers around the epistemic significance of disagreement: when two people who are epistemic peers with each other disagree on an issue what are they required to do epistemically speaking? While some, known as steadfasters, claim that one can justifiably maintain one's belief even in the face of such disagreement, others, known as conciliationists, argue that one should modify one's opinion in light of that disagreement. In past work I demonstrate that these standard approaches are problematic approaches to political disagreements, as they make us vulnerable to cognitive biases (Carlson 2018). In this paper I will outline a more contextualist approach to political disagreement. Following within Jennifer Lackey's justificationist approach and casuistry paradigm 
in medical ethics, I argue that paying attention to a given political disagreement's scope, domain, genealogy, and consequence can be helpful for determining whether to respond to it at the level of our confidence, beliefs, or with policy.

Why develop an epistemology of political disagreement? One reason to limit the scope is simply a matter of modesty. It is possible that this model will be useful for dealing with disagreements in other domains, but I do not wish to argue that this is a totalizing, one-size-fits-all approach to disagreements more generally. It is true that political disagreements have a lot in common with disputes in other domains, and it is possible that my discussion here will be useful elsewhere, but I do not want to argue for that broader claim here.

One problem with this modesty of scope is that it may produce an ad hoc kind of epistemology. I am hesitant about claiming there is something uniquely distinctive property that all and only political disagreements have. That said, one distinctive property about many political disagreements is that the disputes are over what Gerald Gaus calls 'social morality' the rules that structure and govern our social interactions with each other (Gaus 2011: 2-3). Social morality is not as concerned about ethics in a very individualized sense - e.g. what makes for a good life, how a person might conduct themselves virtuously, etc. - but rather when we are permitted to place requirements on others to behave in certain ways, refrain from others, and so on. To illustrate the difference, if two people were having an ethical disagreement over, e.g. the permissibility of having an abortion, they can 'agree to disagree' and go their separate ways without requiring any resolution or consensus. But political disagreements are often not like that. At some point laws and policies on this issue have to be enacted (or not): abortion is either legally permitted or not, publicly funded or not, or some hybrid compromise position in between these options. Adopting any of these options necessarily involves coming to a decision, one that make demands on how people can behave, how they cannot, and so on. Determining the best response to a political disagreement, therefore, is not just a matter of looking for ordinary epistemic or moral justification. Instead one should look at which responses are politically justified, that is, which ones are acceptable to all involved citizens who disagree on a wide number of topics (Chambers 2010).

\subsection{Lackey and justificationism}

For Lackey, what is peculiar in the epistemology of disagreement is that conciliationism seems to deliver the clearly right judgment about some cases, while steadfastness seems just as clearly to give the correct recommendation in others. In some disagreements the disputants are in an epistemically symmetrical relationship with each other, i.e. they are epistemic peers ${ }^{1}$ on some question $p$ in the sense of being equally competent, intelligent, and fair-minded as the other about its domain, as well as being equally familiar with the evidence and argument that bears on it (Lackey 2010: 302). Where the justification seems to be more evenly balanced and neither side has the 'epistemic upper hand' on the other, Lackey thinks

I discuss epistemic peerhood more thoroughly in the political context in §2.4. 
the conciliationist recommending modification of one's doxastic states is likely the more correct strategy. By contrast, steadfast recommendations tend to be correct in situations where there is a 'symmetry breaker' between the two disputants, where one has a larger amount of expertise, knowledge, or information behind their position than their opponent has. No doxastic revision is required of one's view when one disagrees with someone who is either less knowledgeable or well-informed about that situation (Lackey 2010: 318). Lackey takes these two points to mean that the epistemic significance of a disagreement depends on where the preponderance of the justification lies. When considering what to do in a given situation, the real question to ask is: where is the most justification?

Lackey takes this justificationist approach to mean that there is no simple, binary answer about what to do in a particular disagreement, whether to revise one's belief or not (Lackey 2012: 106). Tim Kenyon also thinks the disagreement literature is misguided into thinking that there is a universally applicable answer or general formula to what we should do when we disagree. He aptly describes the issue of disagreement as akin to what to do when handed something:

That there is no single privileged answer to the question, "What ought we to do, epistemically speaking, when faced with a disagreement?" is no more surprising, and certainly no bleaker, than the idea that there is no single privileged answer to the question, "What ought I to do, possessionwise, when somebody hands me something?" It depends on whether I'm being handed a cake or a cobra ... (Kenyon 2019: 236-237).

On Kenyon's understanding of Lackey, we should be skeptical that there are very many broad general principles of how to respond to disagreements, and that is not necessarily a lamentable thing anyway. He suggests instead that we should adopt a more particularist, case-by-case approach to disagreement. But nevertheless, Kenyon takes this case-by-case approach to be a more adequate way of approaching disagreement overall.

\section{Dimensions of political disagreements}

But when asked "What should we do when we disagree?" an "It depends" answer is a pretty unsatisfying one. Depends on what? I want to take up this idea and develop it for political disagreements. I suggest that there are at least four dimensions that are relevant to what one should do (epistemically speaking) in a given political disagreement: domain, scope, genealogy, and urgency. While these dimensions are surely not the only ones worth thinking about, they provide some initially plausible considerations for thinking about how to respond to political disagreements.

For each dimension, I will also give a prima facie gloss of how differences along these dimensions might affect the epistemological evaluation of these respective types. To be clear, there are wide discussions raised in each of these dimensions, and my intention here is not to settle all, or even most, of these controversies. Rather, my 
aim is to show why it is reasonable to think that different disagreement-types may warrant different epistemological evaluations and responses.

\subsection{Domain}

First, political disagreements differ in their domain: some disagreements are about facts about the empirical world, while others are about normative claims about what is valuable or how we ought to act. While treatments of political disagreements have usually centered on normative disputes - e.g. "What steps should we take to address climate change?" conflicts over factual matters - "Is anthropogenic climate change occurring?" - are also becoming increasingly salient in the current political atmosphere (Kappel 2017). Though there are good reasons to be skeptical of a firm distinction between these facts and values (Douglas 2014), for the moment we can treat these as conceptually distinct.

Why think that this difference in domain is important for the epistemological questions surrounding political disagreements? Christopher Robert and Richard Zeckhauser (2011) point out that where a disagreement is over an empirical matter, one possible solution might be to continue the investigation, do some additional research, perhaps to put the two clashing views to an empirical test. Suppose that Ben and Rick are having a disagreement about whether increased government spending is a good policy response to a bad recession. We can determine the preponderance of evidence for this disagreement by examining how compelling each side's normative arguments are. But suppose that their normative disagreement involves a further disagreement about whether increased deficit spending leads to substantially higher inflation. Determining where the preponderance of evidence lies for factual rather than normative disagreement involves not just weighing the arguments like in the normative case but considering whether the empirical data confirms or disconfirms either position. If it turns out that the relevant empirical data tends to confirm Ben's claims about inflation and deficit spending, that seems to be one reason to think his view is epistemically preferable to Rick's. If the empirical record was more mixed and muddled, that might be a reason to think that suspension of belief is perhaps more appropriate.

Insofar as this factual disagreement undergirds their original normative disagreement, the verdict reached on the factual matter can have some impact on how we evaluate the normative dispute as well. If Ben's normative claims are supported by factual ones, but Rick's claims are not, that provides at least some reason to think his normative claims might be preferable as well. Of course, disputes about policyrelevant factual matters are not as neat and tidy as this picture suggests. The relevance of empirical testing should not lead us to be sanguine that political factual disputes are likely resolved by simply appeals to empirical tests - underdetermination and special-pleading are not unique to political disputes (Arabatzis 2008). But I think this example demonstrates that appeal to empirical testing is one way of responding to factual political disagreements that is not available to normative disputes. 


\subsection{Scope}

Second, political disagreements differ in their scope. Many disagreements are deep, in the sense that they are widespread about more than one issue. A staunch libertarian and a democratic socialist do not just disagree on government's place in healthcare, but on a wide range of political issues as well. In the starkest examples, disagreements may go all the way down to differences in philosophical first principles. Robert Fogelin, took 'deep disagreement' to be conflict of fundamental epistemic principles (Fogelin 2005: 8). Other disagreements, though, are more localized in the sense that they take place against a background of general agreement on related issues. Following with the image of 'deep disagreements' we might call these localized disagreements 'shallow'. People who generally agree that universal healthcare coverage is an important policy goal might still disagree about what kind of single payer or multi-payer system best implements that vision.

The scope of disagreement plausibly affects how one should respond to it. Several epistemologists have argued that the conciliatory requirement diminishes as the scope of a disagreement widens. Martin Ebeling (2017) argues that disagreement with an epistemic peer on a political question obligates one to conciliate with them, but if one finds that the dispute is more widespread than originally thought, that diminishes the requirement to conciliate in that situation (Ebeling 2017, 82). Klemens Kappel (2018) has also argued that while disagreements might usually provide some undefeated higher-order evidence that one has made some error, that evidence is not as strong in situations of thoroughgoing, deep disagreement (cf. Pittard 2019) Though deep disagreements might cause some epistemic angst about whether one has made a fundamental mistake or relying on a non-truthconducive principle (Kappel 2018: 11), their presence alone does not undercut the judgment that the other person has made some serious and fundamental errors.

\subsection{Genealogy}

Third, it is plausible to think that political disagreements have different kinds of genealogical sources, particularly from both rational and irrational sources. Many political disagreements are caused by one or more irrational biases influencing at least one of the disputants. For instance, someone who disagrees with the factuality of the Sandy Hook shooting because they rely on a known to be unreliable source like Alex Jones as their primary source of information are likely disagreeing irrationally. Other instances of irrationality might be more subtly problematic, in that a person may hold irrational beliefs but nevertheless ostensibly satisfy epistemic criteria of rational belief. Endre Begby notes that when prejudicial beliefs are a part of a person's background beliefs, it becomes epistemically rational for those beliefs to control, interpret, and evaluate new evidence and experiences (Begby 2013: 94). Motivated reasoning is another prominent cause of many political disagreements. Motivated reasoning describes a bias that skews one's evaluation of the evidence in favor of the beliefs that one already holds (Lord et al. 1979). Antecedent political confidence also interferes with the ability to interpret statistical data correctly, even 
among the most highly mathematically literate people (Kahan et al. 2017). While perhaps less egregiously irrational than the kinds of causes discussed, and others, it is plausible to think that motivated reasoning still produces irrational forms of disagreements (Ancell 2017).

Despite the presence of all of these irrational forces on political disagreements, I think it would be too hasty to claim that all disagreements in this domain are irrational. There does seem to be some possibilities for reasonable political disagreements. One might think that disagreements can be the result of competent reasoning that has survived an extended period of good faith shared deliberation (McMahon 2009: 9). How is it possible that competent, good faith reasoning would nevertheless fail to produce a resolution? Walter Gallie argued that some interminable disputes in domains like politics are over what he terms "essentially contested concepts": ideas whose application and validity are both not resolvable by rational argumentation, but "nevertheless sustained by perfectly respectable arguments and evidence" (Gallie 1956: 169). Essentially contested concepts like 'democracy', 'freedom', have complex components that are open for reasonable individuals to interpret and weigh them differently. When people weigh all of these complex issues independent of each other, they will invariably come to different positions. The essential contestability of political concepts often invites an antirealist or relativist understanding of the dispute about these topics: if there is no uniquely rational or superior way to understand these concepts, then perhaps there is simply no truth about the matter. Though he does not engage with the notion of 'essentially contested' concept, Alvin Goldman (2010) has presented a similar account of how reasonable disagreement can be possible. In a complex domain like politics, discovering one uniquely rational answer to many conflicting issues seems highly implausible. Goldman thinks that norms of inquiry in this difficult domain are likely to be permissive rather than prescriptive, indicating what range of ideas are rationally permissible to believe and enact rather than dictating some unique position. For instance, suppose a moderate libertarian Eric and a moderate liberal Jerry disagree about how to prioritize social well-being and personal autonomy. Even if we assume that there is a truth about how to balance these values, there might still be a range of reasonable or justifiable positions that cluster around the neighborhood of that ideal.

John Rawls (2005) has similarly argued for the possibility of reasonable political disagreements based on the 'burdens of judgment'. For most disagreements, the relevant evidence that bears on a dispute issue is often dispersed, indeterminate, not easily accessible, likely complex and open to more than one reasonable interpretation, and there can be different ways of balancing competing goals or values in light of it. If people are able to independently form their beliefs by using their rational faculties, Rawls thinks we should expect that they will come to different conclusions on the complex matters involving political issues (Rawls 2005: 56-7). To use the earlier example of well-being and autonomy, a moderate libertarian and a moderate liberal will likely disagree about how to prioritize one over the other, not necessarily because one them is being unreasonable or committing a gross error of irrationality, 
but because each freely exercising their own rational capacities will not necessarily come to the same conclusions about how to weigh competing values.

While my intent of this paper is not to comprehensively discuss all aspects of reasonable disagreement, I think Christopher McMahon shows that even a seemingly moral conception of reasonableness has some epistemic components to it. Christopher McMahon helpfully distinguishes between reasonableness as competence and reasonableness as fairness. The former is the more epistemic notion, where one adequately uses one's capacities of reasoning and judgment to develop a position that has prima facie plausibility in light of the available evidence (McMahon 2009: 18). Reasonableness in the second sense is the more moral sense where one makes and abides by fair terms of cooperation and is prepared to make appropriate concessions to others and their viewpoints in cooperative contexts (McMahon 2009: 19). We have reason to think a disagreement is reasonable when, despite extended good faith debate and deliberation, every position is reasonably rejected by at least one participant to the dispute (McMahon 2009: 26). When two people recognize that they are in a persistent and reasonable (in the competence sense) disagreement, if they are reasonable in the fairness sense they are willing to make some kinds of concession or accommodation with those other competent reasoners (McMahon 2009: 23). Political cooperation often requires certain kinds of concessions, but part of making concessions competently involves determining what values justify a particular concession, and how competing interests are brought into equilibrium. Whether a disagreement about justice or fairness is reasonable or not can involve explicating whether the respective sides could be the product of competent exercise of human reason and judgment (McMahon 2009: 25). ${ }^{2}$

Of course, while it might be uncontroversial to say that some political disagreements are reasonable while others are not, giving a clear and principled demarcation between the two will be hotly contested, especially in any particular case. One might think that the demarcation of reasonable and unreasonable is itself a relative idea. Infowars enthusiasts will likely claim that questions about the 9/11 conspiracies or Barack Obama's citizenship are at the very least matters of reasonable disagreement. Given certain background beliefs, these theories can certainly appear reasonable. Climate change skeptics will insist that their skepticism about attributing climate change to human activity is a matter of reasonable disagreement, despite the overwhelming consensus in the opposite direction. Under what conditions are disagreements reasonable? One might say, following Christopher McMahon, that disagreements are reasonable just in cases when all of the disputing parties are competent reasoners who give due consideration to all the relevant factors at play (McMahon 2009: 8-10). But dispute over what factors are relevant is often the very issue in many political disagreements. Though this is not an uncontroversial approach, I think one less problematic way we can understand 'reasonable' disagreement in this context is in a weak, minimalist sense that we have not been able to identify any obvious error in either party's reasoning. This is not to say disagreements that are seen as reasonable actually meet some criteria of reasonableness from an objective,

\footnotetext{
2 My thanks to a reviewer for drawing out this connection.
} 
God's-eye-view perspective, but rather simply that we have not located the error in reasoning yet. Here I draw on an analogy of Robert Talisse's weak epistemological pluralism that says there are value conflicts that do not seem amenable to any kind of rational resolution but not necessarily because of any culpable error on any disputant's part: whether by failure of rationality, error in judgment, or lack of knowledge (Talisse 2012: 24-25). This gives attributions of reasonableness and unreasonableness a sense of provisionality, where disagreement that seemed to be reasonable at one time had a hidden flaw that was not fully appreciated at the time.

There may be other factors involved in how reasonable a disagreement is. For instance, it seems very plausible that social identities play a role here. Social identities place individuals and groups of people in certain social locations, meaning some will have a better understanding of social dynamics than others. More specifically, people in historically marginalized social locations may have an epistemic advantage in the sense of having a better awareness and understanding of systemic oppression (e.g. racism, sexism, etc.) they face than those in more privileged social locations (Wylie 2003). This social location thesis can become relevant when it comes to disagreements that happen between people in different social locations: if A and B disagree about whether a policy is sexist, it seems plausible that one of the participants being a man and the other being a woman could be relevant here. Of course disagreements that are the result of differential social positions might seem reasonable from one perspective - some evidence is available to those in one location but not another - in an important sense I think this would count as an unreasonable disagreement - the social location often being a result of social oppression, marginalization, and other forms of domination. Though I do not have the space to fully defend that claim here, I cannot dismiss a priori the relevance of social identities to political disagreements.

\subsection{A brief note on epistemic peerhood}

In epistemology of disagreement, distinguishing reasonable from unreasonable disagreements is usually taken to distinguish when one is permitted to dismiss a dispute without revising one's beliefs. Not even the most extreme conciliationist thinks that changing one's beliefs is the correct response to every disagreement, even if it is with a patently absurd and irrational conspiracy theorist. Instead, they want to limit their conciliationist prescriptions almost exclusively to cases where epistemic peerhood obtains. In light of peerhood's centrality to the disagreement literature, it is worth saying how this concept fits into this framework I have developed above.

What epistemic peerhood amounts to is itself an open question: I mentioned earlier that according to Jennifer Lackey peerhood is when two individuals are equal in their abilities and expertise and share all the same evidence about the issue in question, but that is not the only view on offer. Others argue that it is when two people are equally reliable or just as likely to get the right answer as their counterpart (Elga 2007). In terms of the dimensions of political disagreements I have laid out above, epistemic peerhood seems to be most relevant to both the genealogy and scope. Considering whether someone is adequately informed on a dispute at issue is 
important for determining how reasonable a disagreement is. Further investigation into another person's reasons for their beliefs may reveal a much deeper disagreement than originally understood or more commonality between them. Discovering that a person gets a wide number of issues wrong (by our lights) or lacks some crucial knowledge might lead one to think that they are not a peer.

Epistemic peerhood plays a significant theoretical role in determining what one should do in response to a political disagreement, as it can help distinguish disagreements that are worth taking seriously from those that obviously are not. But there are several problems with peerhood in the context of political disagreements. First, we often use partisan political affiliation as an indicator of what values a person holds and whether they tend to get important normative questions right or wrong. Suppose Jake, who is generally on the political left on most issues, discovers that Kelsey has affinities with the Republican party in the United States, Alternative für Deutschland (AfD) in Germany or a pro-Brexit party in the United Kingdom. Kelsey's affinities with right-wing parties would signal that he tends to get many important political and moral questions wrong (in Jake's view at least). This signal which would consequently motivate Jake to downgrade Kelsey as less than his epistemic peer (Elga 2007). Ebeling takes a similar position in his dynamic account of peerhood (Ebeling 2016: 151-156). While this kind of downgrading of peer status on the basis of things like party affiliation can be an epistemically acceptable, and even virtuous, response to disagreement, it can, among other things, also make us susceptible to credulous consumption of fake news (Rini 2017).

But the most general problem with peerhood is that it is an idealized kind of epistemic relation that hardly ever occurs between two real-world individuals. It is next to impossible that two people have exactly the same levels of expertise, perfectly shared bodies of evidence, or are equally likely to be correct (King 2012). It is even less likely that two people would recognize or acknowledge that this symmetry obtains between them. This poses a problem for the conciliationist because their prescriptions would only apply in situations that never actually obtain. ${ }^{3}$ Idealizations are not inherently problematic, but the risk is that the conciliationist and the steadfast can simply say, "Well, since peerhood does not obtain in these scenarios, the prescriptions of my view simply do not apply." I worry that we are expending significant energies on epistemologies that have little relevance on how we deal with real world disagreements, since their prescriptions are only relevant for an infinitesimally small slice of real world disagreements wherein peerhood obtains.

I do not have the space here to develop a more suitable account of peerhood that can address these issues in the context of real-world political disagreements. For the moment, though, I think there are interesting epistemological questions about disagreements even when strict peerhood does not occur. Following a suggestion from Nathan King, we might consider a kind of higher-order uncertainty from disagreement generates a puzzle similar to recognized peer disagreement. Even

3 This point may seem to give prima facie plausibility to the steadfast approach, but we should be hesitant to conclude that there is no epistemic significance from all non-peer political disagreements either. As discussed above, Nathan King describes how one can plausibly motivate an epistemic worry from disagreement without peer disagreement obtaining. 
though peerhood does not necessarily occur between the two disputants, it might still be unclear who is in a better epistemic position on that question (King 2012: 250). We might even consider a lower threshold of peerhood as potentially relevant for political disagreements. Andrew Rotondo calls a 'deliberation peer' someone whom one may think is wrong on a lot of important political issues, but nevertheless is someone "worthy of engagement and debate, from whom we can learn, who bring[s] significant arguments and evidence to the table, and whose opinions should not be curtly dismissed as inferior" (Rotondo 2015: 3). Disagreements with a deliberation peer may motivate one to give a position a hearing that may not otherwise be epistemically justified. While there is much more that needs to be said on this point, I think epistemologists of disagreement would be wise to consider how their idealized notion of peerhood cashes out in real-world cases, or begin to theorize about a broader range of cases beyond acknowledged peer disagreements.

\subsection{Consequence}

Finally, some political disagreements are consequential in ways that others are not. Some disagreements are inconsequential in that nothing hangs on their being resolved. Suppose Claire is having a disagreement with a more conservative family member over whether the individual mandate to have health insurance (required by the Affordable Care Act, a U.S. healthcare reform law) is an unconstitutional government overreach or a necessary aspect of a sustainable healthcare policy. In most discussions like this, neither person will provide enough reason to sway the other side; in which case, it seems like the only option is to come to no resolution. And this 'agree to disagree' outcome seems acceptable in part because there are likely no substantial consequences that result from that lack of resolution. Disagreements in informal settings seem to have this (relatively speaking) inconsequential character. But when Senators and Representatives deliberated over this very issue of the individual mandate in their legislative sessions, they likely went over much of the same evidence and arguments that Claire and her family member considered, and yet still had staunch disagreements over the issue. But what is different about the Congressional handling of this disagreement is that they cannot simply 'agree to disagree' in the way that Claire and her family did. And the reason why is simple: how they settled that question would have far wider consequences; their decision would have coercive authority on everyone subject to that law. Even if they failed to pass the bill, even that would have dramatic impacts on millions of people. It seems reasonable, then, to think that when coercive authority is at stake individuals should treat their disagreements differently than in situations where it is not. Andrea Sangiovanni has succinctly articulated the claim that many political disagreements are distinctive in that they make claim to the use of political authority: political disagreements are "not merely about which party is epistemically justified...but which party is politically justified in laying claim to the armature of political authority ... that shapes basic constraints and opportunities" (Sangiovanni 2008: 157).

It seems reasonable then to think that in situations where coercive policy is being developed - as it is in formal legislation processes - more impartial justification is 
required than in lower-stakes discussions of the same issue. The presence of coercive power in formal legislative and judicial contexts therefore plausibly encroaches on how one should respond to that disagreement in those high-stakes situations. The encroachment of coercion on certain political disagreements connects with a prominent theme in contemporary analytic epistemology known as pragmatic encroachment (Fantl and McGrath 2012). Christopher Hookway has articulated a similar notion of encroachment that explicitly draws out an epistemic relevance of practical concerns, namely in when we are justified in gathering more evidence and data or going forward with acting on the available evidence: "the greater the disaster if our actions fail to achieve their purpose, the more evidence we require before we regard the belief as properly justified; the greater the risks attaching to inaction, the readier we are to act on limited evidence" (Hookway 1990: 139).

But even if practical considerations do encroach on our beliefs generally, why think that coercion should be one such practical consideration when it comes to certain political disagreements? Take the following example. Suppose that I have strong justification to believe it is ethically wrong to eat meat and therefore I should adopt a vegetarian diet and lifestyle. I might believe that if other competent moral reasoners considered the relevant factors about this issue, they would come to agree with me, and that the world would be better off if everyone converted to this way of life. But suppose we transposed these ethical beliefs about eating meat into the political domain, that I was a representative considering a law that would prevent people from consuming meat, or enact very stringent animal cruelty laws. Even if we granted the truth of this ethical belief, that would not on its own justify these political actions. Part of what distinguishes political beliefs from other evaluative claims like ethical ones is that the former are aimed at giving us normative instructions of how we ought to cooperate and interact with each other, in particular what should be prevented or allowed. Political morality thus inherently claims authority over others, how people are allowed or prohibited from interacting with each other, in a way that strictly speaking ethical concerns do not. When a disagreement gets transposed into a situation where coercive authority is at issue, it elevates the stakes of the situation. The people subject to the coercive policy would justifiably require a reason for that policy, one that they might not be warranted in asking for otherwise. An ethical belief does not necessarily commit one to the further political claim that the state is warranted in constraining people from acting differently. When political attitudes have this coercive element to them, it is reasonable to think that this elevates the stakes of what kind of justification is necessary for them to be acceptable.

This request for a more impartial level of justification in the context of political morality is often cast as an issue of moral justification, but I think an epistemic aspect is operative as well. Thomas Nagel (1987) has argued for an epistemological division between the public and the private sphere, that we have to seek a more impartial justification for coercive political actions in the public sphere than we do for ordinary moral beliefs in the private space: “...in certain contexts I am constrained to consider my beliefs merely as beliefs rather than as truths, however convinced I may be that they are true, and that I know it" (Nagel 1987: 230). ${ }^{4}$ On

4 Thanks to a reviewer for making this point. 
his account, we do not have to stop thinking that our beliefs are true or justified according to our own comprehensive epistemological perspective, only that from the political perspective they are required to meet some more impartial justification. Importantly, this impartial justification is not necessarily a 'higher' justification. An impartial justification that meets Nagel's standard for the public sphere may still fail to meet a person's more demanding comprehensive epistemological criteria (cf. Bardon 2018). A related epistemic consideration is that the justifications provided have to be acceptable to those who ask for it. As Fabienne Peter puts it, if a policy is to be politically justified it must be justified to the citizens who are subject to it (Peter 2019). If there is no accessible reason available to them to accept some political decision, then we have some good reason to think that decision is not politically justified. It is highly unlikely that everyone would buy into those reasons that I find acceptable, chiefly because reasonable disagreement likely obtains in even the most idealized scenario. In the example of outlawing meat-eating given above, it is more plausible that many reasonable people would not come to the same conclusion as I do about prohibitions on the production and consumption of meat. As a result, one should seek for the more impartial justification that other reasonable people could theoretically accept. Of course, while actual individuals may not find it acceptable some idealized rational individuals would find. (See Vallier 2014, ch. 5).

In surveying these four dimensions, a given disagreement will fall somewhere along each of these dimensions. Thus, there will be deep, irrational, consequential factual disagreements, as well as narrow, reasonable, non-consequential normative disagreements, and all the combinations in between.

\section{Responding to disagreements}

\subsection{Levels}

Responding to a given political disagreement can take place at three distinct levels: confidence, beliefs, and policy. They could take place at the level of confidence. Suppose two women, Briana and Maria, disagree on the justice of legally permitting abortions. Each have divergent credences on the question of the justice of abortion of .2 and .8 , respectively. After discussion with each other, though neither side was defeated by their interlocutor, they were also not able to successfully rebut their arguments either. This disagreement seems to involve what Gerry Gaus calls 'undefeated but unvictorious' proposals, where it is possible for someone to reasonably endorse a position, but also possible for others to reasonably reject it (Gaus 1996: 151-152). As a result, they become less confident in their original position, and therefore revised their respective credences to .3 and .7. We can also talk about the confidence level in less formal terms of going from more to less confident in one's position in light of a disagreement. There is no presumption that credence-conciliation would require any significant alteration to either one's beliefs or their justifications for them. Ballantyne (2013) gives an example of confidenceadjustment without content-adjustment. The empirical research on how much people 
overestimate their own skills and competency may even support the more radical claim that disagreement (at least with one's epistemic equals) should make a person weakly confident that they themselves are wrong (Wiland 2016).

We could also respond at the level of the content of our beliefs. Martin Ebeling exemplifies this level in his case of three legislators (A, B, C) who are deliberating on what the top tax rate should be: A says $40 \%$, B 50\%, C $60 \%$. If A, B, C are peers with each other (i.e. agree on all the factual and normative issues related to this question), then Ebeling thinks the uniquely rational thing for them to do is "achieve full epistemic conciliation" with each other, in this case at 50\% (Ebeling 2017: 173). Though adjusting one's confidence does not necessarily require any alterations of one's beliefs, often they are related: it is difficult to imagine a substantial shift in one's confidence without some attendant alteration in one's beliefs. If someone provides you with a previously unconsidered argument or reason to think one's beliefs are false, that will often result in one becoming less confident in those beliefs. One could also include in this level of conciliation the modification of reasons and justification as part of the content of the belief, where one is incorporating those new justifications into one's belief structure.

Finally, we can respond at the level of a plan or policy. On this level, we are not adjusting our beliefs or confidence in them; instead, we are agreeing on a plan or policy that in some way accommodates some of the representative viewpoints. Policy-level resolutions often take the form of a compromise, where disagreeing parties see the ultimate resolution as a second-best option that is inferior to what their ideal solution would be (Wendt 2016: 14).

What is the relationship between these three levels? These levels of responses are conceptually independent of each other: while becoming less confident in one's beliefs might at some point motivate making some significant modifications of one's first order beliefs, that connection is not necessary. Similarly, modifying at the policy level does not necessarily require substantial revision at the level of one's beliefs or confidence.

\subsection{Epistemic legitimacy of compromises}

Incorporating compromises into an epistemological account raises several questions about the epistemology of political compromises. First, how does a compromise on policy differ from mere bargaining that is part and parcel of the normal operations of politics? The concern about mere compromise is that this creates a kind of modus vivendi agreement. Rawls (2005) speaks of a modus vivendi as an agreement wherein two parties resolve a conflict only out of pursuit of their own interests. They do not come to terms because they have converged on some justification that all parties find acceptable but because they are not able to pursue their own interests or achieve their own ideological goals in any other way. I suggest that compromises can be an epistemic kind of modus vivendi, where there are no epistemic reasons to justify it, but only practical ones. Second, compromises are epistemically peculiar because they are by their very nature viewed as the secondbest option. While there might be practical justification for adopting a compromise 
(May 2005) is there any distinctively epistemic justification these second-best compromises might have?

There are several ways to develop what epistemic justification for compromises might look like. Federico Zuolo and Giula Bistagnino (2018) argue that a compromise can be epistemically motivated by recognizing the other party as an epistemic peer, or an epistemic equal. While this is a helpful response, I think there is more we can say about the epistemic justification of compromises.

The alternative to an epistemic modus vivendi I have in mind here is that the agreement they eventually come to should meet some kind of epistemic legitimacy criterion. What might epistemic legitimacy look like? Epistemic legitimacy can be located in two different sources: in the final outcomes or decisions that a political body generates or in the procedures by which the body comes to its decisions. This first source would be a kind of substantial legitimacy: an agreement A is epistemically legitimate only if all parties to it can locate a reason in their set of beliefs that would make A acceptable to them. The second source is a procedural kind of legitimacy, where the source is legitimate because it was produced by an epistemically fair procedure. Fabienne Peter points out that these sources of legitimacy are not mutually exclusive, as one can have a substantive (or 'rational') proceduralism that combines both sources as conditions of epistemic legitimacy: a compromise must be rationally justified as well as decided by an epistemically fair procedure (Peter 2007: 338-339). David Estlund (2009) has defended this kind of hybrid position he calls epistemic proceduralism on the grounds that, if his account is correct, it shows that democratically fair procedures are not just good in themselves but also serve one of the central epistemic goals of achieving true beliefs. One might worry, though, that looking for compromises that are epistemically legitimate in Estlund's substantial sense is unrealistic, as it would require more agreement than we could expect to get in a situation where resorts to a compromise decision. In fact, since participants will likely view their original pre-compromise position as more fully true than the compromise itself, requiring agreement that the end decision is the truest option seems implausible.

I think the more purely proceduralist account developed by Peter would be more realistic account of legitimacy in situations where epistemic compromises are usually called for. One can find a policy outcome unacceptable in its content, while still thinking that it is acceptable because the procedure by which it was decided is acceptable. Following her account of pure epistemic proceduralism, what is required for compromises to be legitimate is not only that all parties to the dispute can participate in the deliberation and decision-making process under conditions of political and epistemic fairness, that but also that all are able to "regulate public deliberation at the fact-gathering and analysis stages" (Peter 2007: 343-4). Furthermore, one can see these kinds of democratic procedure as themselves compromises: Aurelia Bardon (2018) has argued that democratic procedures are themselves best viewed as epistemic compromises that do not have to be acceptable as a more comprehensive epistemology. For instance, suppose one is a religious person who believes that revelation is a vitally important epistemic source for one's 
beliefs about God and the world, but one is considering a set of rules and procedures that do not permit revelation as a valid source of evidence in its proceedings. On Bardon's view, it is not inconsistent for this religious person to affirm this public epistemology as acceptable in the public sphere while rejecting it as a satisfactory epistemology outside of that limited scope. As long as everyone agrees that these kinds of procedures are acceptable for use in deciding public or political questions, they can reject these procedures in favor of a more expansive epistemology to answer comprehensive questions that fall outside of the public sphere.

\section{Justificationism revisited}

\subsection{Beyond Lackey}

To connect this discussion of political disagreements to Lackey's justificationism, to address the different kinds of political disagreement outlined above, we have to look beyond Lackey's account. First, answering Lackey's specific question about where the balance of epistemic justification lies would likely rely on asking at least some of these questions like "How much justification do we need? Is it a factual disagreement or normative one? Narrow or wide?" Why might these considerations be relevant to determining where the preponderance of the evidence lies and how we should respond to a given disagreement? It is true that a disagreement's domain, scope, or stakes do not tell us anything directly about where the balance of justification lies in a given case or what we should do in light of that. But I want to suggest that these elements of a disagreement can indicate what information is relevant as evidence. The inflation case discussed in $\$ 2.1$ already demonstrates how determining the domain of a disagreement is helpful in adjudicating it.

Scope can be similarly helpful in determining how to respond to a disagreement. Suppose that Laura and Siray are having a disagreement about whether a given shutdown order is an advisable policy in response to a coronavirus outbreak. Suppose that while Laura's support for the shutdown is based on mainstream epidemiologists' recommendations, but Siray opposes it because he gets his news about COVID-19 exclusively from watching conspiracy theorists like Alex Jones and Youtube videos like "Plandemic". His use of unreliable sources seems like a good reason to think their disagreement is fairly deep but also unreasonable, and that Laura's is epistemically preferable. Conversely, suppose Siray is a reasonably well-informed and competent philosopher of science and has come to the judgment that epidemiologists' data are insufficient to support a stringent shutdown. He and Laura might still have a fairly deep disagreement, but if he can provide some reasonable defeaters that undermine her position, then it might be reasonable to think that Laura should move closer to his view, or perhaps become less confident in her original position.

I think we can improve upon Lackey's justificationism. I will call this development 'political justificationism'. This view has two parts: one can respond to political disagreements at three different levels: confidence, content, and policy. Determining at what level to respond will likely depend on the specific features of 
the disagreement is: what it's about, how widespread it is, its genealogical sources, and its consequence.

\subsection{Problems for political justificationism}

A natural question that arises for this position is how these two pieces interact. How do the features of a disagreement determine what level of response it should receive? One might hope that one could give a general account of political disagreement. "Having an unreasonable value disagreement? Stick to your guns at all levels!" "Having a reasonable factual disagreement? Adopt a compromise on a policy that's acceptable to all parties involved." I want to lay out two reasons to be skeptical that construing political justificationism as this kind of generalist epistemology is plausible. This pessimistic attitude is motivated, first, by how many different kinds of disagreement there are. While I think the diversity detailed in $\$ 2$ is a virtue for political justificationism, it is not a comprehensive account. Political justificationism presents a complex menagerie of disagreements, but it must be noted that these dimensions still elide numerous further complications and nuances that we find when we examine individual cases. The nuances of these specific disagreements could plausibly affect how we should respond to them.

Take the domain dimension distinguishing disagreements over facts and norms. Not all policy-relevant facts are the same. While well-informed expert opinion tends to coalesce in some static domains, it tends to diverge wildly in others (Shanteau 2015). Politically relevant facts are thus likely just as variable in this same respect. But what would follow epistemically from the claim that fewer disagreements arise in the former domains than in the latter ones? Should we characterize disagreements in discordant domains as more reasonable than those where convergence more regularly happens? Such a sweeping claim seems presumptuous to make from the philosophical armchair.

Furthermore, factual and value disagreements are themselves often so closely intertwined it is often difficult to pinpoint where to locate a particular disagreement on the domain spectrum. Disagreement about whether life begins at conception might appear to be factual dispute related to abortion, but, even if it is a factual question, it often spills over into more normative claims about whether to prioritize the value of a woman's autonomy or the life of a fetus, the interpretation and relevance of sacred scriptures, and so on. Adjudicating the reasonableness of abortion disagreement may require determining the reasonableness of those more specific disputes.

Further nuances arise when we consider the scope dimension more closely. All deep disagreements are also not all deserving of the same kind of response. Some deep disagreements are the result of belief polarization, where individuals become more extreme in their attitudes. It is a common assumption that belief polarization is generally epistemically undesirable, perhaps even irrational. For instance, Thomas Kelly (2008) has argued that the presence of belief polarization in our beliefs should give us pause about how confident we are in them. But we should be wary of taking the epistemic undesirability of these kinds of deepening disagreement as a general principle. There are some empirical instances (Lindell et al 2017) of 
deepening disagreement in deliberative forums that do not seem to have many of the epistemic defects that are normally ascribed to polarizing beliefs. There are also lots of complexities along the urgency dimension as well. While disagreements over an annual budget might be urgent in some important sense, they are likely not as exigent as disagreements over a human right legislation. The differences even within tokens of the same type of disagreement make me skeptical that they warrant the same kind of response.

I think what follows from this diversity of political disagreements makes it difficult, if not impossible, to expect a general epistemology of political disagreements from the philosophical armchair. In one sense it is uncontroversial to say that there is not a general response to disagreements. Not even the most extreme conciliationist or steadfaster suggests that their prescriptions apply to all disagreements. But the more specific claim I am defending is that we should be skeptical of very broad generalities about how we should respond even to different types of political disagreement. If there is an account that can do justice to the diversity of these disagreements - both between the different types and also tokens of the same type - it may depend on the particular features of the context in which the disagreement takes place. Luckily, we have a model for this kind of reasoning from the casuistry tradition in bioethics that is skeptical of starting with abstract general moral principles to decide what to do in medical decisions (Jonsen and Toulmin 1988, Jonsen 1995, Arras 1991). On the generalist view they oppose, making ethical decisions involves starting from universally applicable moral principles, and then applying them in particular circumstances. Practitioners of casuistry, or casuists, argue that this generalist top-down methodology is too insensitive to the particular nuances of cases. They instead favor evaluating situations on a more case-by-case basis. When evaluating what to do in a given situation, they begin with a thorough description of the features of a case. Albert Jonsen, Mark Siegler, and William Winslade have developed a four-box analysis method that conceptualizes the relevant aspects of a medical case: a patient's clinical indications (Given her condition, how can she be benefited or not harmed?), her quality of life (What are the prospects for her having a decent quality of life?), the patient's preferences (Is the patient's right to make an informed choice being respected?), and other contextual features (What procedure and outcome is fair and just to all parties involved?) (Jonsen, Siegler, and Winslade 2006: 7). While general moral principles like autonomy, beneficence, non-maleficence, and justice can certainly play a role in these kinds of deliberations (see Jonsen 1995), casuistry relies more heavily on reasoning by analogy to decide what should be done.

\subsection{Political justificationism: \\ a casuistic epistemology of political disagreement}

Following the four-box method from casuistic medical ethics, I propose a similar four-box method (displayed in Figure 1) for analyzing political disagreements. While it might be difficult to provide many broad principles how to deal with the complex types of disagreement, I will sketch out how political justificationism's 
analysis might be helpful. Let us examine a case of disagreements that are deep and reasonable. Suppose we return to the case mentioned in $\$ 3.1$ of Briana and Maria deliberating over whether abortion should be legally permissible. After they discuss the reasoning behind their positions, neither is able to provide a decisive defeater for the other person's position. However, each of them seems to be peers, in at least a minimal sense that they have both demonstrated themselves to be competent, wellinformed, reflective, and good-faith reasoners about this issue. Since they seem to be on an epistemic par with each other, that gives them some reason to think that their respective positions might not be the only reasonable ones or that they may have made some kind of error. And nothing hinges on their failure to agree; they are not deciding policy or ruling on current legal case. In light of all these features a moderate epistemic revision seems like a permissible response. They might moderately reconsider how confident they are about their respective positions. Of course, such judgments of reasonableness and moderation are defeasible, as this case is abstractly and idealistically sketched. It is possible that Brian or Maria provided a defeater that the other person should have recognized but failed to. If their discussion revealed that either Briana and Maria's views were founded on accurate or misleading information or that one (or both) of their attitudes were being influenced by some cognitive biases that would provide some reason for a different judgment.

But not all putatively reasonable disagreements will necessarily get the same treatment. Suppose city council members, represented by Lori and Toni, are considering implementing a shutdown order to deal with a pandemic. Suppose Lori represents those council members who think the shutdown recommended by a majority of epidemiologists is the best. Toni, on the other hand, represents those who think that a shutdown is not the way to go, and their conclusion is not based on listening to unqualified cranks or conspiracy theorists, but on well-informed, competent epidemiologists who happen to dissent from that majority opinion. As far as each side can tell, the other side is not substantially more or less competent and well-informed than they are. But even though Toni and Lori represent what seems to be a reasonable disagreement, their dispute is more consequential than Briana and Maria's, as the council members will have to make an ultimate decision one way or the other, one that will have dramatic effects on others. In a less dire situation, it might be reasonable to put off making that choice while they can gather more information that might help resolve their dispute. But in a crisis situation like a pandemic, one often does not have the luxury of researching policy proposals indefinitely. They have to make the choice given the information available to them.

What should we make of political disagreements that seem more unreasonable? One example to consider is the Finnish deliberative poll discussed by Marina Lindell et al (2017). The researchers wanted to compare the differences between those who deliberate in like-minded groups and those who are in more heterogeneous groups. Prior research suggested that the participants in like-minded groups would engage in more polarization than the heterogeneous group. Based on a survey of their initial attitudes on immigration coming into the deliberation, they were then randomly allocated to like-minded groups, heterogenous groups, or a control group. In this 


\begin{tabular}{|c|c|}
\hline $\begin{array}{l}\text { Domain } \\
\text { - What is the disagreement about? } \\
\text { - How persistent is disagreement in this } \\
\text { domain? } \\
\text { - Does this disagreement involve any } \\
\text { observational predictions? } \\
\text { - What kind of evidence bears on this } \\
\text { disagreement? }\end{array}$ & $\begin{array}{l}\text { Scope } \\
\text { - How widespread is the disagreement? } \\
\text { - What are the places where evidence is } \\
\text { not shared? } \\
\text { - In what sense are the disputants epistemic } \\
\text { peers, if at all? }\end{array}$ \\
\hline $\begin{array}{l}\text { Genealogy } \\
\text { - What is the source of the disagreement? } \\
\text { - Under what circumstances did this } \\
\text { disagreement arise? } \\
\text { - What biases are being manifested by } \\
\text { participants in this disagreement? } \\
\text { the there any identifiable cognitive biases } \\
\text { dispute? } \\
\text { - How might social identities contribute } \\
\text { to this disagreement? }\end{array}$ & $\begin{array}{l}\text { Urgency } \\
\text { - Does this disagreement need to be } \\
\text { resolved? } \\
\text { - Are there any likely consequences to } \\
\text { a failure to agree? } \\
\text { - Are there any likely consequences } \\
\text { by coming to an agreement too quickly? } \\
\text { - If a disagreement is urgent, what sort of } \\
\text { features does it need to have? }\end{array}$ \\
\hline
\end{tabular}

Figure 1. A 4-box approach to political disagreement.

study, participants who polarized their opinions did not display many of the features that ordinarily make polarization problematic from a normative standpoint: they formed their beliefs in heterogenous groups - so there was very little possibility for a groupthink dynamic - and showed normal levels of information absorption and learning (Lindell et al. 2017: 39). One might expect those who moderated their position post-deliberation would be the ones who learn more, display more empathy, and become more open-minded. But in this case, the polarizers displayed many of the same behaviors and dispositions as those who moderated their opinion (Lindell et al. 2017: 40).

How would the four-box method approach this case? Is that polarized attitude shift epistemically justified? The first thing that stands out here is the apparent absence of epistemically undesirable biases or forces: there were not any obvious group effects or individual biases that were influencing people in epistemically problematic ways. Regarding urgency, they are not policy-makers crafting immigration policy so there are no implications from them failing to agree, nor are they coming together to make a collective conclusion or decision either. Since many of the epistemically problematic features of polarization did not show up in this case, that provides some reason to think this polarizing behavior was more reasonable than it originally seemed. One suggestion is that the participants were exhibiting preference clarification where, as a result of deliberation and discussion, individuals come to have a clearer, more reflective understanding of what their actual commitments and preferences are 
(Lindell et al 2017:23). Preference clarification may sometimes result in convergence and moderation of opinions, but it may also result in polarization.

The authors conclude, rightly in my estimation, that we should not assume that polarization as a result of preference clarification is necessarily bad, epistemically speaking. One might wonder, though, about the long-term epistemic effects of such further polarization; while the clarification of their preferences might be worthwhile and desirable epistemic achievement in isolation, one concern is how that development might affect subsequent interactions. Will this polarization incline them to further retreat into ideological informational silos that entrench their views and make them less open to hearing the other side, or less likely to see those they disagree with as reasonable?

\section{Conclusion}

I began this paper with the aim of developing a more adequate epistemology of political disagreement, specifically through Lackey's justificationist approach. I have argued that what follows from her approach is that there is neither one kind of political disagreement, nor even one level at we can respond to them. While these points might seem rather banal, I think the importance of noticing the diversities at play illustrates the difficulty in developing a generalist approach to political disagreement that seems to be the default assumption in much discussion of epistemology of disagreement. The alternative I have sketched out here suggests that figuring out how to properly respond to political disagreement is likely going to require paying attention to the fine-grained details of its type and its circumstances and then a good deal of deliberation (internally but interpersonally) about which level of response - confidence, content, or policy - is warranted.

\section{Acknowledgments}

My thanks to David Ingram, Paul Moser, Kristen Irwin, Nathanael Smith, Jeffrey Hoops, Oscar Piedrahita, audiences at the Ryerson University and the University of Tartu, Bruno Mölder, and two anonymous reviewers for providing helpful feedback on earlier presentations of this paper.

Address:

Jay Carlson

Loyola University-Chicago

$7531 \mathrm{~N}$ Winchester Ave

Chicago, IL 60626, U.S.A.

E-mail: Rcarlson3@luc.edu 


\section{References}

Ancell, Aaron (2017) Essays in political disagreement. Dissertation. Duke University.

Arabatzis, Theodore (2008) "Experiment". In S. Psillos and M. Curd, eds. The Routledge companion to philosophy of science, 159-170. London: Routledge.

Arras, John (1991) "Getting down to cases: the revival of casuistry in bioethics". Journal of Medicine and Philosophy 16, 29-51.

Ballantyne, Nathan (2013) "Counterfactual philosophers". Philosophy and Phenomenological Research $88,2,368-387$.

Bardon, Aurelia (2018) "Public epistemology as a compromise: why should we agree to disagree?". In Christian Røstbull and Theresa Scavenius, eds. Compromise and disagreement in contemporary political theory, 146-160. Routledge: New York.

Begby, Endre (2013) “The epistemology of prejudice". Thought: A Journal of Philosophy 2, 2, 90-99.

Carlson, Jay (2018) "Epistemology of disagreement, bias, and political deliberation: the problems for a conciliatory democracy". Topoi. doi: https://doi.org/10.1007/s11245-018-9607-8

Chambers, Simone (2010) “Theories of political justification”. Philosophy Compass 5. 11, 893-903.

Douglas, Heather (2014) "Values in science". In Nancy Cartwright and Eleonora Montuschi, eds. Philosophy of social science: a new introduction, 162-184. Oxford: Oxford University Press.

Ebeling, Martin (2017) Conciliatory democracy: from deliberation toward a new politics of disagreement. New York: Palgrave Macmillan.

Elga, Adam (2007) "Reflection and disagreement". Noûs 41, 3, 478-502.

Estlund, David (2009) "Epistemic proceduralism and democratic authority". In Raf Geenens and Ronald Tinnevelt, eds. Does truth matter? Democracy and public space, 15-27. Dordrecht: Springer.

Fantl, Jeremy and Matthew McGrath (2012) "Pragmatic encroachment - it's not just about knowledge". Episteme 9, 1, 27-42.

Fogelin, Robert (2005) “The logic of deep disagreements". Informal Logic 25, 1, 3-11.

Gallie, Walter B. (1956) "Essentially contested concepts". Meetings of the Aristotelian Society 56, $167-198$.

Gaus, Gerald (1996) Justificatory liberalism. New York: Oxford University Press.

Gaus, Gerald (2011) The order of public reason: a theory of freedom and morality in a diverse and bounded world. Cambridge: Cambridge University Press.

Goldman, Alvin (2010) "Epistemic Relativism and Reasonable Disagreement". In Richrad Feldman and Ted Warfield, eds. Disagreement, 187-214. New York: Oxford University Press.

Hookway, Christopher (1990) Scepticism. London: Routledge.

Johnsen, Albert and S. Toulmin (1988) Abuses of casuistry. Berkeley, California: University of California Press.

Jonsen, Albert (1995) "Casuistry: an alternative or complement to principles?". Kennedy Institute of Ethics Journal 5, 3, 237-251.

Jonsen, Albert, M. Siegler, and W. Winslade (2006) Clinical ethics: a practical introduction to ethical decisions in clinical medicine. New York: McGraw-Hill.

Kahan, Daniel, E. Peters, E. Dawson, and P. Slovic (2017) "Motivated numeracy and enlightened selfgovernment". Behavioural Public Policy 1, 54-86. 
Kappel, Klemens (2017) "Fact-dependent policy disagreements and political legitimacy". Ethical Theory and Moral Practice 20, 2, 313-331.

Kappel, Klemens (2018) "Higher order evidence and deep disagreement". Topoi. doi: https://doi. org/10.1007/s11245-018-9587-8

Kelly, Thomas (2008) "Disagreement, dogmatism, and belief polarization". Journal of Philosophy 105, $10,611-633$.

Kenyon, Tim (2019) “Disagreement”. In David Coady and James Chase, eds. Routledge handbook of applied epistemology, 233-246. New York: Routledge.

King, Nathan (2012) "Disagreement: what's the problem? Or a good peer is hard to find". Philosophy and Phenomenological Research 85, 2, 249-272.

Lackey, Jennifer (2010) “A justificationist view of disagreement's epistemic significance”. In Adrian Haddock, Alan Millar, and Duncan Pritchard, eds. Social epistemology, 298-325. Oxford: Oxford University Press.

Lackey, Jennifer (2012) "What's the rational response to everyday disagreements". The Philosopher's Magazine 59, 101-106.

Lindell, Marina, A. Bächtiger, K. Grönlund, K. Herne, M. Setäla, and D. Wyss (2017) "What drives the polarization and moderation of opinions? Evidence from a Finnish citizen deliberation experiment on immigration". European Journal of Political Research 56, $23-45$.

Lord, Charles, L. Ross, and M. Lepper (1979) "Biased assimilation and attitude polarization: the effects of prior theories on subsequently considered evidence". Journal of Personality and Social Psychology 37, 2098-2109.

May, Simon Căbulea (2005) "Principled compromise and the abortion controversy". Philosophy and Public Affairs 33, 4, 317-348.

McMahon, Christopher (2009) Reasonable disagreement: a theory of political morality. New York: Cambridge University Press.

Nagel, Thomas (1987) "Moral conflict and political legitimacy". Philosophy and Public Affairs 16, 3, 215-240.

Peter, Fabienne (2007) "Democratic legitimacy and proceduralist social epistemology". Politics, Philosophy \& Economics 6, 3, 329-353.

Peter, Fabienne (2019) "Epistemic self-trust and doxastic disagreements". Erkenntnis 84, 1189-1205.

Pittard, John (2019) "Fundamental disagreements and the limits of instrumentalism". Synthese 196, 5009-5038.

Rawls, John (2005) Political liberalism. Expanded ed. New York: Columbia University Press.

Rini, Regina (2018) "Fake news and partisan epistemology". Kennedy Institute of Ethics Journal, 27, 2, 43-64.

Robert, Christopher and Richard Zeckhauser (2011) The methodology of normative policy analysis. (Harvard Kennedy School Faculty Research Working Paper Series, RWP11-004.) John F. Kennedy School of Government, Harvard University. Available online at $<$ https://dash.harvard. edu/handle/1/4669672>. Accessed on July 15, 2020.

Rotondo, Andrew (2015) "Disagreement and intellectual skepticism". Australasian Journal of Philosophy 93, 2, 251-271.

Sangiovanni, Andrea (2008) "Justice and the priority of politics to morality". Journal of Political Philosophy 16, 2, 137-164. 
Shanteau, James (2015) "Why task domains (still) matter for understanding expertise". Journal of Applied Research in Memory and Cognition 4, 3, 169-175.

Talisse, Robert (2012) Pluralism and liberal politics. (Studies in Contemporary Philosophy.) New York: Routledge.

Vallier, Kevin (2014) Liberal politics and public faith: beyond separation. New York: Routledge.

Wendt, Fabian (2016) Compromise, peace and public justification political morality beyond justice. London: Palgrave Macmillan.

Wiland, Eric (2016) "Peer disagreement and the Duning-Kruger effect". Episteme 14, 4, 481-498.

Wylie, Alison (2003) "Why standpoint matters". In Sandra Harding and Robert Figueroa, eds. Science and other cultures: issues in philosophies of science and technology, 26-48. New York: Routledge.

Zuolo, Federico and G. Bistagnino (2018) "Disagreement, peerhood, and compromise". Social Theory and Practice 44, 4, 593-618. 